Contract No. and Disclaimer:

This manuscript has been authored by Savannah River Nuclear Solutions, LLC under Contract No. DE-AC09-08SR22470 with the U.S. Department of Energy. The United States Government retains and the publisher, by accepting this article for publication, acknowledges that the United States Government retains a non-exclusive, paid-up, irrevocable, worldwide license to publish or reproduce the published form of this work, or allow others to do so, for United States Government purposes. 


\title{
EFFECTS OF TRITIUM GAS EXPOSURE ON POLYMERS
}

\author{
E.A. Clark, E.B. Fox, M.C. Kane", G.C. Staack \\ Savannah River National Laboratory, Building 773-A, Aiken, South Carolina, 29808, elliot.clark@srnl.doe.gov \\ "currently at Sandia National Laboratories, Livermore, California 94551
}

Effects of tritium gas exposure on various polymers have been studied over the last several years. Despite the deleterious effects of beta exposure on many material properties, structural polymers continued to be used in tritium systems. Improved understanding of the tritium effects will allow more resistant materials to be selected. Currently polymers find use mainly in tritium gas sealing applications (eg. valve stem tips, O-rings). Future uses being evaluated including polymeric based cracking of tritiated water, and polymer-based sensors of tritium.

\section{INTRODUCTION}

The beta decay of tritium is ionizing radiation that significantly damages polymeric materials that tritium contacts. Although selecting polymers for use in tritium handling systems is avoided where possible, there are always components in tritium systems that require the unique properties of polymers that have no non-polymeric alternatives. This paper describes studies aimed at understanding tritium effects on structural polymers, on polymers potentially useful for tritium processing, and polymers being investigated for use as tritium sensors. The radiolytic production of gas is also presented.

\section{TRITIUM EFFECTS ON POLYMERS FOR GAS SEALING APPLICATIONS}

\section{II.A. Tritium Effects on Material Properties}

Studies of exposure of ultrahigh molecular weight polyethylene (UHMW-PE), polytetrafluoroethylene (PTFE, a trade name is Teflon ${ }^{\circledR}$ ), and the polyimide Vespel ${ }^{\circledR}\left(\right.$ Dupont $\left.{ }^{\circledR}\right)$ to initially $1 \mathrm{~atm}$. Tritium at ambient temperature (in closed containers) reveal significant differences among these materials in resistance to tritium and amount of gas radiolytically produced ${ }^{1}$. Dynamic mechanical analysis (DMA) revealed that the storage modulus of UHMW-PE increases with exposure time up to about one year and then decreases (up to two years exposure). The storage modulus of PTFE also increased with tritium exposure time until after nine months the samples broke during DMA testing ${ }^{1}$. The loss modulus of both UHMW-PE and PTFE were significantly lower at temperatures greater than ambient. The DMA properties of Vespel® were unaffected by tritium exposure, even after two years of tritium exposure ${ }^{1}$.

Samples of four formulations (Nordel ${ }^{\circledR}$ and Royalene ${ }^{\circledR}$, each with and without carbon black filler) of ethylene propylene diene monomer elastomer (EPDM), were exposed to initially one atmosphere tritium gas at ambient temperature in closed stainless steel containers. The glass transition temperature increased significantly as measured by DMA (Fig.1) 2,3,4 $^{2}$ The samples became brittle in a bend test after about half a year exposure time. The glass transition temperature of filled EPDM formulations after one year was lower than that for unfilled formulations, showing that filler material improves resistance to radiation-induced degradation.

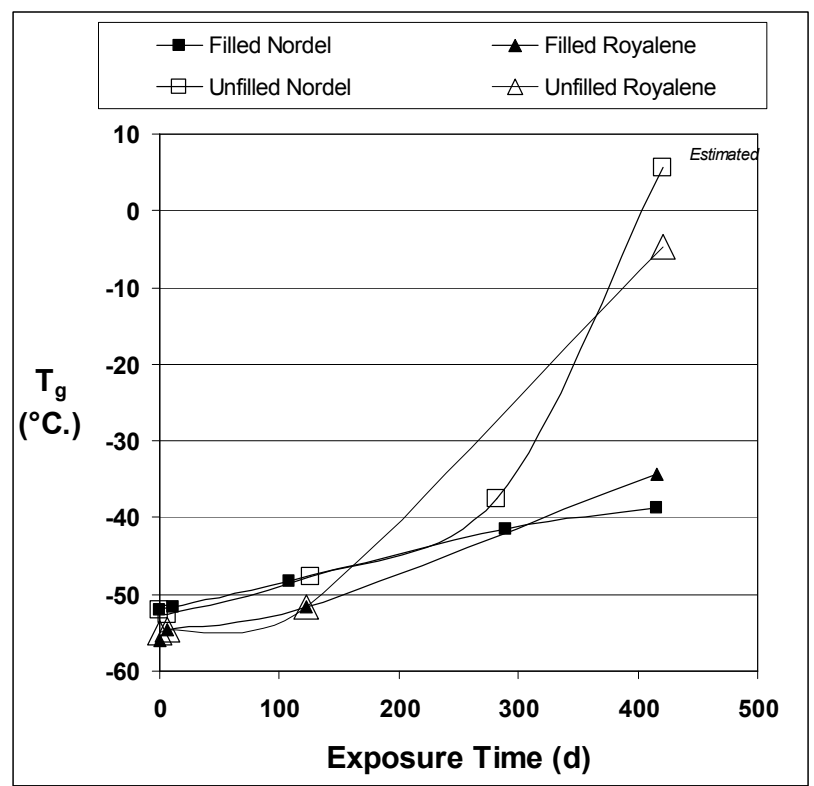

Fig. 1. Glass Transition temperature $\left(T_{g}\right)$ of four EPDM formulations as a function of tritium exposure time. Carbon black filler. Glass transition temperature measured by ASTM E1640. 


\section{II.B. Radiolytic Gas Production}

Over about two years, the pressure in closed containers of UHMW-PE increased about nine-fold; the majority of gas produced was protium ${ }^{1}$. During the same time, the total pressure of the PTFE sample containers lowered slightly- this is believed to be caused by formation of TF that is "sticky"- condensed on the walls of the container". Although the total pressure in the Vespel ${ }^{\circledR}$ containers remained constant during exposure, the composition of the gas became about $50 \%$ tritium, revealing that Vespel ${ }^{\circledR}$ does interact with tritium gas.

During the EPDM study, protium was produced during exposure- there was a factor of three increase in container pressure and the composition (as measured by a low atomic number sensitive mass spectrometer) became mainly protium ${ }^{4}$ (Fig. 2). At the beginning, the entire atmosphere is tritium $\left({ }^{3} \mathrm{H}_{2}\right)$ and the polymer contains all protium $\left({ }^{1} \mathrm{H}\right)$. When tritium molecules dissolve in the polymer and then beta decay, the damaged polymer releases protium, the dissolved tritium and released protium isotopically exchange, and the released protium permeates out of the samples into the gas. Initially, most of the gas produced is the isotopologue HT $\left({ }^{1} \mathrm{H}^{3} \mathrm{H}\right)$ (Fig. 2 ), then over time most of the produced gas becomes protium $\left(\mathrm{H}_{2}\right.$ or $\left.{ }^{1} \mathrm{H}_{2}\right)$ (Fig. 2).

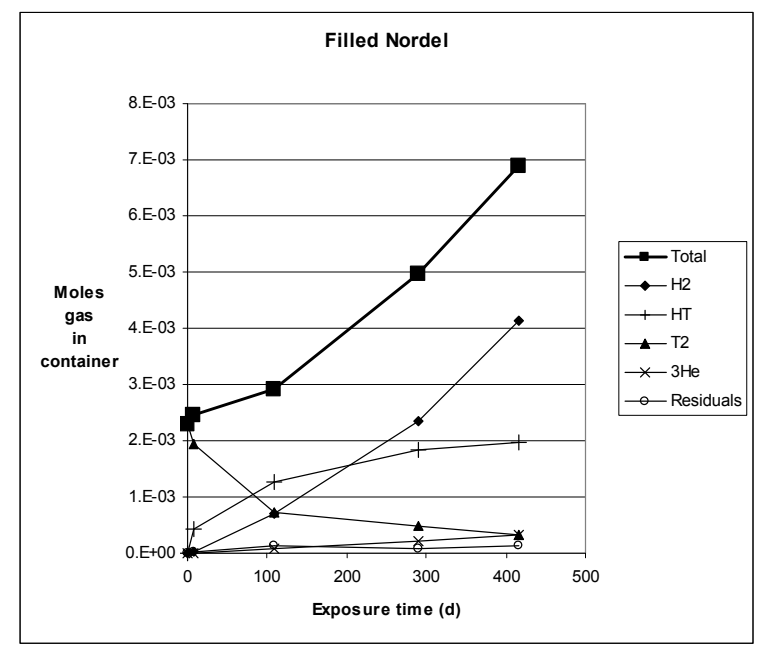

Fig. 2. Moles of gas in container at various tritium exposure times in days. Individual species detected and also total moles as indicated in legend. Filled Nordel shown, other EPDM formulations (unfilled Nordel $\AA$, filled and unfilled Royalene $®)$ similar.

\section{TRITIUM EFFECTS ON NAFION ${ }^{\circledR}$ FILMS}

The tritium stability of Nafion ${ }^{\circledR}$ is of interest due to its use in proton exchange membranes to recover tritium from tritiated water by electrolysis ${ }^{5}$. Traditionally, gamma radiation exposure of Nafion ${ }^{(B}$ has been used as a surrogate for beta radiation sources 6,7 because of the availability of resources and difficulty in handling tritiated water a laboratory setting during electrolysis. However, facilities in our laboratories enabled us to test the durability of the polymer formulation in one atmosphere of tritium gas. On-going studies are being used to determine if gamma radiation can be viably used a surrogate radiation source and preliminary data is presented here.

\section{III.A. Calculation of energy deposition of tritium in polymers}

To compare gamma radiation with beta radiation exposures, the beta dose rate of tritium in polymers is estimated. It is assumed that for beta radiation, the energy of each decay is dispersed throughout the polymer. To calculate the energy deposition rate of tritium in the polymer, it is assumed that the polymers absorbed 10 $\mathrm{Ci} / \mathrm{cc}^{8}$ and the average decay energy of tritium is $5.7 \mathrm{keV}^{9}$ in the following

$$
10 \frac{\mathrm{Ci}}{\mathrm{cm}^{3}}\left(3.7 \mathrm{e} 10 \frac{\mathrm{d} / \mathrm{s}}{\mathrm{Ci}}\right)=3.7 \mathrm{e} 11 \frac{\mathrm{d} / \mathrm{s}}{\mathrm{cm}^{3}}\left(5700 \frac{\mathrm{eV}}{\mathrm{d}}\right)=2.11 \mathrm{e} 15 \frac{\mathrm{eV}}{\mathrm{s}^{*} \mathrm{~cm}^{3}}
$$

The density of Nafion ${ }^{\circledR}$ and PTFE is about $2 \mathrm{~g} / \mathrm{cm}^{3} 5$, then:

$$
\frac{2.11 \mathrm{e} 15 \mathrm{eV} / \mathrm{s}^{*} \mathrm{~cm}^{3}}{2 \mathrm{~g} / \mathrm{cm}^{3}}=1.05 \mathrm{e} 15 \frac{\mathrm{eV}}{\mathrm{s} * \mathrm{~g}}
$$

If $1 \mathrm{rad}$ is equal to $100 \mathrm{ergs}_{\text {deposited }}$ per $\mathrm{g}$ of matter and 1 erg is equal to $6.242 \mathrm{e} 11 \mathrm{eV}$, then:

$$
\frac{1.05 \mathrm{e} 15 \mathrm{eV} / \mathrm{s} * \mathrm{~g}}{6.242 \mathrm{e} 11^{\mathrm{eV}} / \mathrm{erg}}=\frac{1.69 \mathrm{e} 3 \mathrm{erg} / \mathrm{s} * \mathrm{~g}}{100 \mathrm{erg} / \mathrm{rad}}=16.9 \frac{\mathrm{rad}}{\mathrm{s}}
$$

Exposures doses can then be directly compared to gamma radiation based on exposure times.

\section{III.B. Comparison of beta and gamma irradiation of Nafion ${ }^{\circledR}$}

Utilizing the calculations described above, Nafion ${ }^{\circledR}$ films were exposed to one atmosphere of tritium at comparable dose levels to gamma exposed samples. The change in the storage modulus was then measured using 
the DMA. In both cases of gamma and beta exposure of the Nafion ${ }^{\circledR}$ films resulted in an initial increase of storage modulus with dose, then the modulus decreased with increasing dose. The films exposed to one atmosphere of tritium displayed a considerably larger storage modulus decrease before failure (Fig.3). The increase in storage modulus may be attributed to an increase in cross-linking, while the decrease is indicative of chain scission.

The differences in damage to the polymer may be attributed to the strength of the incident radiation. Gamma rays will penetrate through the film, while the beta rays may be captured in the polymer. When the beta rays are captured, secondary damage to the polymer may occur as the beta ray travels within polymer structure.

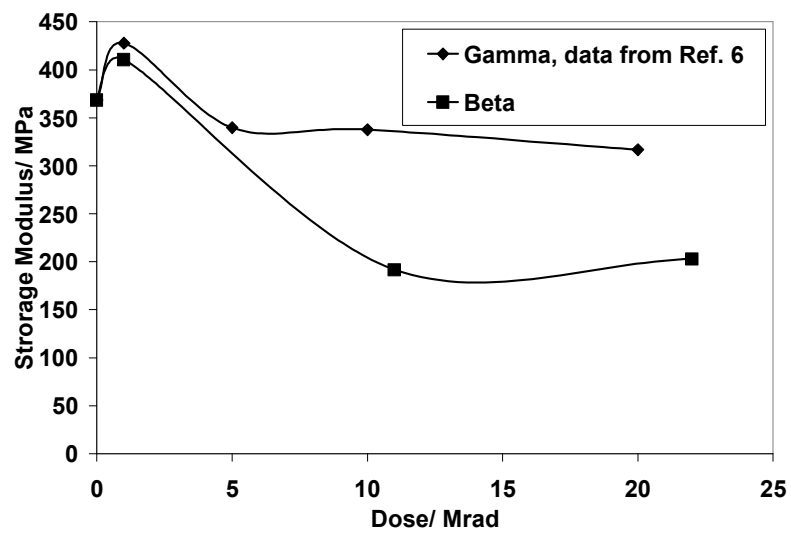

Fig. 3. Storage modulus of Nafion ${ }^{\circledR}$ at $60^{\circ} \mathrm{C}$ after exposure to both gamma irradiation by a ${ }^{60} \mathrm{Co}$ source and beta irradiation by 1 atmosphere of tritium gas.

\section{TRITIUM EFFECTS ON CONDUCTIVE POLYMERS}

A great deal of interest has developed in recent years in the area of conducting polymers due to the high levels of electrical conductivity that can be achieved, some comparable to that of metals ${ }^{10}$. The electron transfer mechanism is generally accepted as one of electron "hopping" through delocalized electrons along the conjugated backbone. There have been a few studies on using conducting polymers for radiation detection ${ }^{11,12}$, although there have been no reports on the effects of tritium gas on conducting polymers.

In this study, surface coatings of 1) polyaniline doped with dinonylnaphthalenesulfonic acid (PANi) and 2) poly(3,4-ethylenedioxythiophene) doped with poly(styrenesulfonate) (PEDOT-PSS) were deposited on a substrate of polyester (PET) by a vendor. These sheets were cut into strip samples and were exposed to pure tritium gas in stainless steel exposure containers for varying lengths of time. The containers were attached to a tritium gas manifold and loaded with either $10^{4}$ or $10^{5} \mathrm{~Pa}$ pressure of tritium gas and held for between 0.1 and 1000 hours. After exposure, the samples were removed from the exposure container and the surface conductivity of the conductive film was measured using a surface conductivity meter with small sample concentric ring probe, either in a tritium hood (open-air environment, denoted as "in Air" in Figures 4 and 5) or in a nitrogen glove box (oxygen-free environment, denoted as "in $\mathrm{N}_{2}$ " in Figs. 4 and 5). The surface conductivity was also measured before exposure and the ratio of the tritium exposed conductivity to the unexposed conductivity (in both air and nitrogen environments) was the parameter used to characterize the effects of tritium on surface conductivity (Figs. 4,5). The equivalent dose of tritium (in rad) absorbed by the samples was calculated using the same method as the equivalent dose of Nafion discussed above ${ }^{8}$. Note that because of the pressure difference, the largest equivalent dose for the $10^{5} \mathrm{~Pa}$ exposure (Fig. 4) is ten times that of the $10^{4} \mathrm{~Pa}$ exposure (Fig. 5).

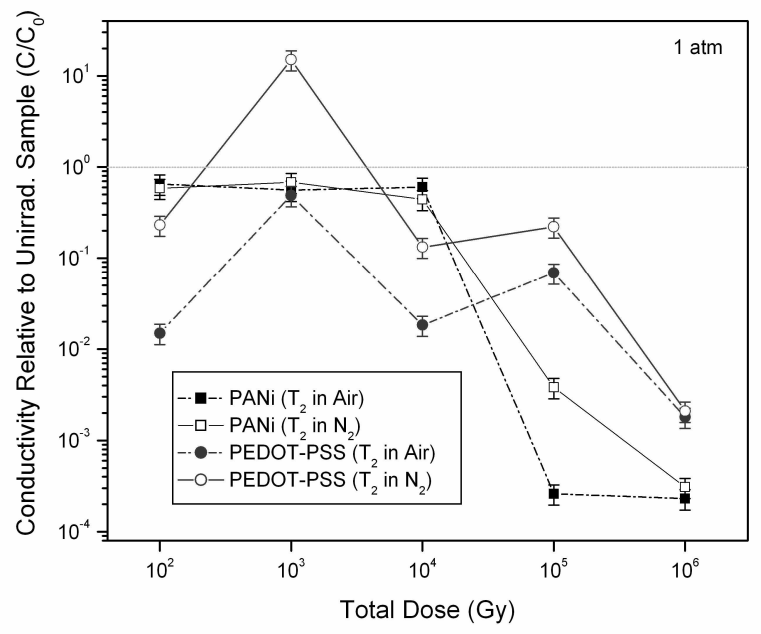

Fig. 4. Relative Conductivity (irradiated Conductivity divided by unirradiated conductivity) as a function of estimated dose for tritium exposure at $10^{5} \mathrm{~Pa}$ pressure tritium gas.

The two different exposure pressures of tritium gas were used to simulate two dose rates of beta radiation. It is clear that the lower dose rate (Fig. 5) caused much more severe chain scission (reduction in conductivity) than the higher dose rate (Fig. 4). This dose rate effect has been observed by others ${ }^{13}$. 


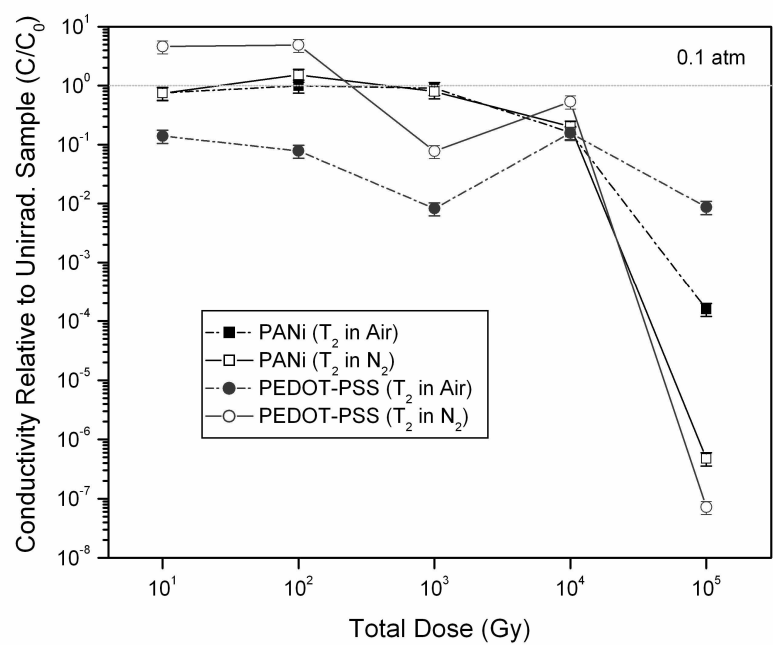

Fig. 5. Relative Conductivity (irradiated Conductivity divided by unirradiated conductivity) as a function of estimated dose for tritium exposures at $10^{4} \mathrm{~Pa}$ pressure tritium gas. (Note the total dose scale is a factor of 10 less than Fig. 4.)

It is assumed that there are two simultaneous competing mechanisms for change in electrical properties of PANi and PEDOT-PSS when in the presence of an ionizing radiation field - chain scission and crosslinking ${ }^{14}$. Chain scission results in a decrease in conductivity while cross-linking results in an increase.

Based on the results of the beta (tritium gas) irradiation of conducting polymers, it can be speculated that PANi degrades in a radiation field mainly via chain scission due to conductivity decrease and PEDOT-PSS has similar amounts of chain scission and cross-linking in the range of doses investigated based on the increase and decrease of surface conductivity at various total doses. It may be concluded from these results that oxidation occurs on a long time scale for PANi and a short time scale for PEDOT-PSS based on the time taken for measurement, or that there is a greater concentration of free radicals present on the surface after irradiation on the PEDOTPSS sample than PANi, which can participate in the oxidation mechanism ${ }^{15}$.

\section{REFERENCES}

1. E.A. CLARK, K.L. SHANAHAN, Fusion Science and Technology, 52(4), pp. 1007-1011 (2007).

2. E.A. CLARK, G.C. STAACK, Fusion Science and Technology, 54(2), pp. 576-579 (2008).

3. E.A. CLARK, "Tritium Effects on Dynamic Mechanical Properties of Polymeric Materials", in
Effects of Hydrogen on Materials Proceedings of the 2008 International Hydrogen Conference, ed. Brian Somerday, Petros Sofronis, Russell Jones, ASM International, Materials Park OH USA, pp. 726-734 (2009).

4. E.A. CLARK, "Effects of Tritium Gas Exposure on EPDM Elastomer", report SRNL-STI-2009-00801, Savannah River National Laboratory, 11 December 2009.

5. S. D. GREENWAY, E. B. FOX and A. A. EKECHUKWU, "Proton exchange membrane (pem) electrolyzer operation under anode liquid and cathode vapor feed configurations," Int. J. Hydro. Energy, 34, 6603 (2009).

6. E. B. FOX, S. D. GREENWAY and E. A. CLARK, "Radiation stability of nafion membranes used for isotope separation by proton exchange membrane electrolysis," Fusion Sci. Tech., 57, 103 (2010).

7. Y. IWAI, T. YAMANISHI, M. NISHI, T. YAGI and M. TAMADA, "Durability of irradiated polymers in solid-polymer-electrolyte water electrolyzer," $J$. Nuc. Sci. Tech., 42, 636 (2005).

8. E. A. CLARK Waste characterization of polymeric components exposed to tritium gas. Report WSRCSTI-2008-00078, OSTI ID: 927597, Savannah River National Laboratory, Aiken, S.C. (15 February 2008).

9. Doe handbook on tritium handling and safe storage; DOE-HDBK-1129-99; U.S. Department of Energy: Washington, D.C., http://www.hss.doe.gov/NuclearSafety/techstds/stand ard/hdbk1129/hdbk1129.pdf, 1999; pp DOE.

10. M. GERARD, A. CHAUBEY, and B.D. MALHOTRA. Biosensors \& Bioelectronics 17, 345 (2002)

11. W.M. DE ACEVEDO, A.P. DA COSTA LIMA, E.S. DE ARAUJO, Radiation Protection Dosimetry 84, 77 (1999).

12. A.P. LIMA PACHECO, E. S ARAUJO, W.M. DE ACEVEDO, Materials Characterization 50, 245 (2003).

13. B.A. BRISKMAN, E.R. KLINSHPONT, V.F. STEPANOV, K.B. TLEBAEV. Journal of Spacecraft and Rockets 41, 360 (2004).

14. R. WOODS, A. PIKAEV, Applied Radiation Chemistry: Radiation Processing, John Wiley and Sons, Inc., New York, NY (1994).

15. M.C. KANE, R.J. LASCOLA, E.A. CLARK, Radiation Physics and Chemistry 79, 1189-1195 (2010). 